\section{Intravascular Ultrasound-Validated Mechanical Stress of the Aorta on Anomalous Origin of Coronary Artery - A Possible Sign of Angina -}

Hajime Shinohara, MD; Masahisa Shimpo, MD, PhD; Hiroaki Watanabe, MD; Shinichi Toriumi, MD; Takahiro Komori, MD, PhD; Satoshi Hoshide, MD, PhD; Kazuomi Kario, MD, PhD

\begin{abstract}
A 62-year-old Japanese woman with no remarkable medical history was observed to have an abnormal ECG at a medical examination. Although there were no subjective symptoms, a treadmill exercise stress test showed marked ST depression in leads II, III, aVF, and V2-V6. Exercise stress myocardial scintigraphy with ${ }^{99 \mathrm{~m}} \mathrm{Tc}$-tetrofosmin confirmed the findings of myocardial ischemia in the anterior walls of the left ventricle (Supplementary Figure). Coronary artery computed tomography revealed that the left coronary artery (LCA) was branching from a slightly higher site of the noncoronary cusp, and the left main trunk was bent at 90 degrees immediately after branching (Figure A,B). Cardiac catheterization was performed, and no severe stenosis was found. When observed by intravascular ultrasound (IVUS), the LCA had a slit-like ostium and was further deformed in the systolic phase (Figure C,D; Supplementary Movie). We determined that the cause of angina was a hemodynamic problem associated with the coronary artery anomaly and flexion deformation of the coronary artery due in part to aortic pulsation.
\end{abstract}

The release of catecholamines due to sympathetic nerve activation, such as during exercise, increases the stroke volume and heart rate. As a result, the aortic root is further expanded and the left main trunk is further deformed, resulting in increased hemodynamic stress and the induction of myocardial ischemia. Because the patient had been asymptomatic until the age of 62, we decided to administer drug therapy with the $\beta$-blocker bisoprolol. The patient has subsequently been without any symptoms or cardiac events for $>5$ years. We should recognize the importance of not only assessing morphological abnormalities, but also validating mechanical stress on coronary arteries with IVUS.

\section{Disclosures}

K.K. is a member of Circulation Journal's Editorial Team.

\section{Data Availability}

Not applicable.

\section{Supplementary Files}

Supplementary Movie. IVUS video of left coronary artery.

Please find supplementary file(s);

http://dx.doi.org/10.1253/circj.CJ-21-0310

Received April 4, 2021; revised manuscript received June 14, 2021; accepted June 17, 2021; J-STAGE Advance Publication released online July 29, 2021 Time for primary review: 10 days

Division of Cardiovascular Medicine, Department of Medicine, Jichi Medical University School of Medicine, Shimotsuke, Japan

Mailing address: Masahisa Shimpo, MD, PhD, FJCS, Division of Cardiovascular Medicine, Department of Medicine, Jichi Medical University School of Medicine, 3311-1 Yakushiji, Shimotsuke 329-0498, Japan. E-mail: shimpo@jichi.ac.jp

All rights are reserved to the Japanese Circulation Society.

For permissions, please e-mail: cj@j-circ.or.jp

ISSN-1346-9843
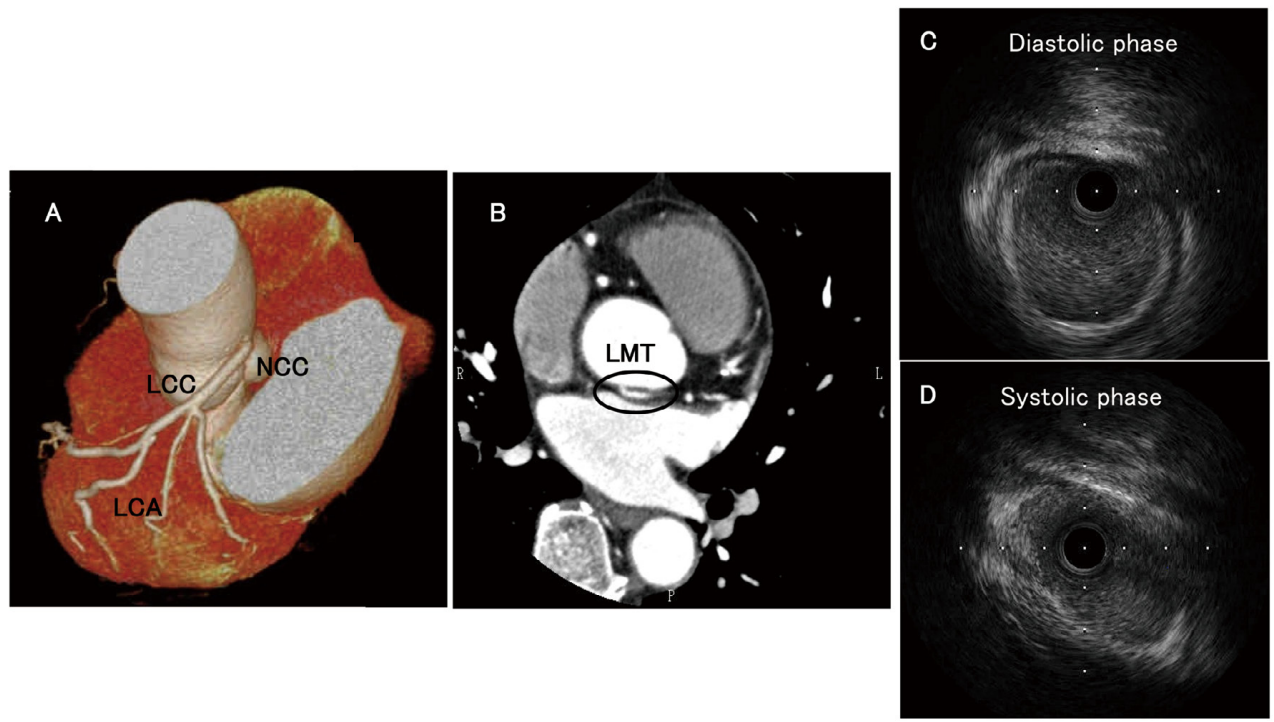

Figure. (A,B) Coronary artery CT. (C, D) IVUS images on diastole and systole. LCA: left coronary artery, LMT, left main trunk, IVUS, intravascular ultrasound; LCC, left coronary cusp, NCC, noncoronary cusp. 